\title{
REFLEXÕES SOBRE O CONCEITO DE DIREITOS FUNDAMENTAIS DE GREGORIO PECES-BARBA
}

\section{REFLEXIONES SOBRE EL CONCEPTO DE DERECHOS FUNDAMENTALES DE GREGORIO PECES-BARBA}

\begin{abstract}
${ }^{1}$ Marcos Leite Garcia
\section{RESUMO}

O presente artigo tem como objetivo fazer um estudo sobre a concepção dos Direitos Fundamentais na obra de Gregorio Peces-Barba. Para tal faz-se necessário a análise do contexto da evolução da teoria dos direitos fundamentais de Gregorio Peces-Barba: seu historicismo, sua primeira concepção dualista e sua posterior evolução para a concepção tridimensional. Foi realizada pesquisa, com posterior tratamento de dados, utilizando-se os métodos indutivo e dedutivo. A partir da obra do autor em questão chega-se a importantes critérios basilares para a determinação de um conceito de Direitos Fundamentais.
\end{abstract}

Palavras-chave: Direitos fundamentais, Direitos humanos, Dimensões, Reflexões, Conceito

\section{RESUMEN}

El presente artículo tiene como objetivo hacer un estudio sobre el concepto tridimensional de los derechos fundamentales en la obra de Gregorio Peces-Barba. Para tal es necesario el análisis del contexto de la evolución de la teoría de los derechos fundamentales de Gregorio Peces-Barba, su historicismo, su primer concepto del dualista y su evolución posterior para el concepto tridimensional. La investigación fue realizada, con posterior tratamiento de los datos, usándose los métodos inductivos y deductivos. Del estudio de la obra del autor en cuestión llégase a criterios fundamentales importantes para la determinación de un concepto de derechos fundamentales.

Keywords/Palabras-claves/Mots-clés: Derechos fundamentales, Derechos humanos, Dimensiones, Reflexiones, Concepto

\section{Introdução}

1 Doutor em Direito pela Universidad Complutense de Madrid - Espanha. Professor da Universidade do Vale do Itajaí. Universidade do Vale do Itajaí -UNIVALI, Santa Catarina. Brasil - E-mail: mleitegarcia@terra.com.br 
Uma das teses mais conhecidas de Gregorio Peces-Barba (1995-I, p. 146), é a que sustenta que “(...) os direitos fundamentais são um conceito histórico do mundo moderno que surge progressivamente a partir do trânsito à modernidade". Essa é uma das máximas da teoria dos Direitos Fundamentais do professor Gregorio Peces-Barba, de extrema importância na fundamentação dos direitos e que determina sua metodologia para a abordagem do tema. Nesse sentido, também leciona o jusfilósofo italiano Norberto Bobbio (2004, p. 25) os "direitos não nascem todos de uma só vez. Nascem quando devem ou podem nascer". E justifica o professor de Turim, que os Direitos fundamentais "(...) Nascem quando o aumento do poder do homem sobre o homem cria novas ameaças à liberdade do indivíduo ou permite novos remédios para as suas indigências". Segue justificando o mesmo que "(...) ameaças que são enfrentadas através de demandas de limitação de poder; remédio que são providenciados através da exigência de que o mesmo poder intervenha de modo protetor". Nesse sentido, a concepção do professor espanhol madrilenho Gregório Peces-Barba (1982, p. 4) sobre o trânsito à modernidade diz que:

[...] o trânsito à modernidade é um momento revolucionário, de profunda ruptura, mas ao mesmo tempo importantes elementos de sua realidade já se anunciavam na Idade Média, e outros elementos tipicamente Medievais sobreviveram ao fim da Idade Média, neste trânsito à modernidade e até o século XVIII, aparecerá à filosofia dos direitos fundamentais, que como tal, é uma novidade histórica do mundo moderno, que tem sua gênese no trânsito à modernidade, e que, por conseguinte, participa de todos os componentes desse trânsito já sinalizados, ainda que sejam os novos, os especificamente modernos, os que lhe dão seu pleno sentido ${ }^{1}$.

Gregorio Peces-Barba, desde suas próprias palavras ${ }^{2}$, assim como também Luigi Ferrajoli, considerava-se discípulo e seguidor de Norberto Bobbio e de uma nova forma

\footnotetext{
1 Gregório Peces-Barba, com relação à expressão trânsito à modernidade, encontra dificuldade na delimitação cronológica do período em razão das divergências de interpretação quanto à origem da Idade Média e onde se localiza o início do Renascimento. Considerou, portanto, mais adequado utilizar o termo para o período histórico que se iniciará no século XIV e chegará até o século XVIII ou XIX. Evidentemente que dependendo da região em que estaria sendo aludida, uma vez em algumas regiões as condições de superação do feudalismo se darão antes, como na Itália e Inglaterra e em outras mais atrasadas será depois como na França e na Alemanha; assim sendo na península ibérica ainda mais atrasadas. Em algumas latitudes o feudalismo adentra até o século XX, quiçá o XXI. GARCIA, 2008, p. 194.

2 Em diversas oportunidades o professor Gregorio Peces-Barba se declarou como um discípulo de seu mestre Norberto Bobbio. Por exemplo: PECES-B ARBA, 2000, p. 25; e PECES-BARBA, 1998. p. 20.
} 
de positivismo a partir do Estado Constitucional de Direito nascido no pós Segunda Guerra Mundial. Será então no entorno do desenvolvimento do novo ideário do Estado Constitucional ou democrático e social de Direito que o positivismo-constitucionalismo garantista de Ferrajoli ou o chamado positivismo corrigido ou ético de Peces-Barba ${ }^{3}$ irão se desenvolver. Em suma, são teorias que podem ser classificadas como pertencentes ao contexto do neopositivismo jurídico. Peces-Barba a partir de sua teoria dualista que segundo seu discípulo e colaborador Rafael de Asís Roig ${ }^{4}$ em uma segunda e mais importante etapa de sua obra passará a ser trialista ou tridimensional; uma vez que o professor de Madrid a partir dos anos de 1990 passa a lecionar que os mesmos devem ser tratados a partir de uma concepção tridimensional que leva em consideração as suas dimensões axiológicas, normativas e fática ${ }^{5}$.

Dentro exatamente desse contexto Liborio Hierro, um dos seus professores colaboradores desde os seus inícios de Universidade Complutense, considera a Teoria do Direito de Gregorio Peces-Barba como uma Teoria do Direito do Estado Constitucional $^{6}$. A Teoria dos Direitos Fundamentais do professor Peces-Barba deve

\footnotetext{
3 Assim se posiciona Peces-Barba no que se refere a sua Teoria do Direito em seu debate com a obra de Gustavo Zabrebelski. Veja-se em: PECES-BARBA, Gregorio. Derecho sociales y positivismo jurídico: escritos de Filosofía Jurídica y Política. Madrid: Dykinson/Universidad Carlos III de Madrid, 1999. p. 123. Veja-se também no mesmo sentido os seguintes textos: PECES-BARBA, Gregorio. La democracia en España. p 91-92; PECES-BARBA, Gregorio. La España civil. Barcelona: Galaxia Gutenberg, 2005. p. 127 ; e da mesma forma o texto de seu ex-aluno e discípulo Javier Dorado (2008, p. 429-453).

${ }^{4}$ ASÍS ROIG, Rafael de. Sobre el concepto y el fundamento de los Derechos: una aproximación dualista. Madrid: Dykinson/Universidad Carlos III de Madrid, 2001. p. 19. No mesmo sentido em: ASÍS ROIG, Rafael de. La concepción dualista de los Derechos Fundamentales en la teoría de Gregorio PecesBarba. In: VV.AA. Entre la Ética, la Política y el Derecho. Estudios en homenaje al profesor Gregorio Peces-Barba. Vol. I. Madrid: Dykinson, 2008. p. 393.

${ }^{5}$ Muitos foram os autores que trabalharam desde uma Teoria do Direito de forma tridimensional, destacase entre todos a obra do brasileiro Miguel Reale, que de forma similar concebia as dimensões fática, normativa e axiológica. Importante chamar a atenção que o professor Peces-Barba nunca chamou a sua própria teoria de tridimensional, essa é uma interpretação de seus discípulos e dos comentaristas de sua obra.

${ }^{6}$ Um dos pontos mais importantes da obra do professor e jusfilósofo espanhol Gregorio Peces-Barba que merece ser destacado certamente é o aludido fato de que Liborio Hierro considera a Teoria do Direito de Gregorio Peces-Barba como uma Teoria do Direito do Estado Constitucional, e que sua corrente de pensamento hoje não resulta nada extravagante. Em tempos recentes de um acirrado e radical neoliberalismo e também de modismos na teoria do direito, os chamados neopositivistas, assim rotulados por alguns, acabaram ficaram um pouco fora de moda (um absurdo as modas também na academia, uma forma de manipulação). Gregorio Peces-Barba sempre esteve longe dos radicalismo e por isso mesmo desde sempre foi vitima dos ataque mais injustos: seja dos neoliberais, que o acusam de comunista e de outras adjetivos impublicáveis; ou da esquerda mais radical, que o consideram injustamente apenas um liberal. Na verdade são posições radicais, e algumas até mesmos raivosas, que não merecem atenção, mas que mencionamos por havermos também sido vitimas de preconceitos por estudar sua obra. HIERRO, 2008. p. 649-650.
} 
ser exatamente situada no contexto de um novo paradigma de positivismo jurídico, ético ou corrigido conforme suas palavras, e seu historicismo, desenvolvido por suas linhas de evolução ${ }^{7}$, certamente que é progressista e não conservador como são os historicismos mais tradicionais ${ }^{8}$.

\section{Direitos Fundamentais no pensamento de Gregorio Peces-Barba}

O pensamento de Gregorio Peces-Barba sobre os Direitos Fundamentais tem como ponto inicial a histórica distinção e separação entre a ética pública e a ética privada. Os direitos fundamentais, como desenvolvimento dos valores das conquistas humanas civilizatórias, como indica Peces-Barba são a vertente subjetiva central da moralidade pública para alcançar a proteção do indivíduo frente as ameaças da tirania e autoritarismo do Estado e também da Igreja ${ }^{9}$.

Será a ética pública da Modernidade a proposta de Peces-Barba, desde uma Teoria da Justiça, para que o poder político que a incorpore seja legítimo e o Direito assumido e posto seja justo. Toda a argumentação a favor da justiça incorporada pelo Direito tem como raiz comum a legitimidade do poder e a ética pública com a que se relacionam. E a máxima dessa ética pública é a dignidade da pessoa humana. Todos os

\footnotetext{
${ }^{7}$ Peces-Barba (1995-I, p. 146-198) leciona sobre as chamadas linhas de evolução dos direitos que são relatadas nos seguintes temas: a) processo de positivação: a passagem da discussão filosófica ao Direito positivo (primeira geração, direitos de liberdade); b) processo de generalização: significa a extensão do reconhecimento e proteção dos direitos de uma classe a todos os membros de uma comunidade como conseqüência da luta pela igualdade real (direitos sociais ou de segunda geração); c) processo de internacionalização: ainda em fase embrionária, de difícil realização prática e que implica na tentativa de internacionalizar os direitos humanos e que ele esteja por cima das fronteiras e abarque toda a Comunidade Internacional; d) processo de especificação: pelo qual se considera a pessoa em situação concreta para atribuir-lhe direitos seja como titular de direitos como criança, idoso, como mulher, como consumidor, etc, ou como alvo de direitos como o de um meio ambiente saudável ou à paz (direitos difusos ou de terceira geração).

${ }^{8}$ Convencionalmente o historicismo é confundido com teorias conservadoras que pregam uma neutralidade axiológica, e são contrários às filosofias da história ou mesmo como uma reação negativa à filosofia do Iluminismo. Pelo contrário, a obra de Peces-Barba e do grupo que publicou uma longa coleção de História dos Direitos Fundamentais pela editora Dykinson não podem ser assim classificados. Veja-se a obra completa Historia de los Derechos Fundamentales - dirigida por Peces-Barba e que foi um dos grande projetos de sua vida, nela estão os estudos dos principais autores e colaboradores de sua escola de direitos fundamentais. São os organizadores da obra: Gregorio Peces-Barba, Eusebio Fernández, Rafael de Asis, Francisco Javier Ansuátegui Roig. Obra em 22 volumes do século XVI ao XX.

${ }^{9}$ Em diversos momentos de sua obra, Peces-Barba leciona sobre a importância da distinção no alvorecer do ideal dos direitos fundamentais, na formação do direito natural racionalista que é base dos atuais direitos fundamentais. De forma mais didática e direta em: PECES-BARBA, p. 513-544, 1997; PECES- BARBA, 1995-II. 156 p.
} 
objetivos devem convergir para favorecer o desenvolvimento de condições dignas da pessoa humana em todas as esferas de sua vida. Em especial destacam-se duas: a) fixar e realizar por si mesmas sua própria ética privada, como destaca o próprio professor espanhol; e b) antecipando - com o objetivo de dar ênfases aos direitos sociais - dita ética pública será desenvolvida através dos dois séculos seguintes ao primeiro processo de positivação dos direitos fundamentais para a concretização de um mínimo existencial digno do ser humano, trata-se do fundamental tema das necessidades básicas. Não resta dúvida que este será o natural caminho do desenvolvimento da dignidade da pessoa humana a partir do processo de generalização (generalizar os Direitos e a dignidade a todos os membros da Sociedade).

No que se refere à ética privada, diz Peces-Barba (1995-II, p. 75-79) que a justiça e o Direito não podem conter a obrigação de comportamentos que conduzem diretamente ao bem, à virtude e à felicidade, todas questões subjetivas que estão no âmago da ética privada de cada pessoa. A pessoa deve ser livre para escolher sua ética privada, no contexto atual refere-se ao respeito da autonomia da vontade de cada um. Deve ser garantido que cada pessoa tenha condições suficientes para que possa fazer uso de sua liberdade de eleição e assim de decidir, por si mesma, sobre seu objetivo, caminho ou plano de vida. Também deve-se evitar dentro do possível que obrigações jurídicas derivadas de critérios de justiça possam confrontar-se com deveres de consciência no âmbito da ética privada (caso das objeções de consciência).

Não resta dúvida que a partir do novo paradigma do Estado Constitucional de Direito, os direitos fundamentais passam a legitimar todo o sistema de normas. Ademais, importante destacar que os direitos fundamentais são conquistas históricas da humanidade e somente foram possíveis a partir de uma série de acontecimentos marcantes que levaram a uma mudança na estrutura da sociedade e na mentalidade do ser humano (Garcia, 2007, p. 4). Por isso mesmo como fundamentam os italianos Riccardo Guastini (2003, p. 50-51) e Luigi Ferrajoli (2008, p. 102-109) uma das características do novo paradigma do Direito do pós guerra é a exatamente a rigidez constitucional. Assim faz parte do novo paradigma aludido a chamada por Ferrajoli esfera do não-decidível, esfera do indecidível, ou do núcleo duro que chama-se no Brasil de cláusulas pétreas, ou ainda território proibido por Norberto Bobbio, coto vedado por Ernesto Garzón Valdés; em suma: Direitos Fundamentais constitucionalizados e que não podem ser abolidos ou revogados. 
Gregório Peces-Barba (1995-I, p. 103) analisa que os direitos fundamentais são remitidos a uma pretensão moral justificada sobre traços importantes derivados da idéia de dignidade humana que tão-somente a partir da sua recepção no Direito positivo poderá ter a sua finalidade efetivada. Devida a essa característica alcança-se a compreensão dos direitos fundamentais de uma visão integral do fundamento e do conceito. Sua inseparável conexão se produz porque o direito tem uma raiz moral que se indaga por intermédio da fundamentação, mas não são tais sem pertencer ao ordenamento e poder, assim ser eficazes na vida social, realizando a função que os justifica. Neste sentido, a moralidade e juridicidade formam o âmbito de estudo necessário para a compreensão dos direitos fundamentais.

Para o professor espanhol (1995-I, p. 104) não teria sentido falar da fundamentação de um direito que não seja logo suscetível em nenhum caso de integrar- se no Direito positivo, e tão pouco terá sentido falar do conceito de um direito ao que não se lhe possa encontrar uma raiz ética vinculada às dimensões centrais da dignidade humana. Nos direitos fundamentais a moral e o direito estão entrelaçados e a separação os faz incompreensíveis. A compreensão dos direitos fundamentais, da moral e do direito, aparecerem conectados pelo Poder. Os direitos fundamentais que se originam e se fundam na moralidade lançam-se no direito pela intervenção do Estado. Esta é a sua concepção dualista inicial ${ }^{10}$.

\footnotetext{
${ }^{10}$ Leciona o professor Peces-Barba (1995-I, p. 104) que sem o apoio do Estado esses valores morais não se convertem em Direito positivo, e, por conseguinte, carecem de força para orientar a vida social em um sentido que favoreça sua finalidade moral. No entanto, quando a moralidade incorporar-se ao Direito positivo está frente a uma pretensão moral justificada que constituem a Filosofia do direito fundamental. E, a partir da pressão dada pelos cidadãos o Estado assume seu papel para formar parte do Direito positivo. Dessa maneira, antes do primeiro processo de positivação levado a cabo com as revoluções burguesas do século XVIII, necessário tratar de um anterior processo de evolução que seria o qual chamamos de processo de formação do ideal dos direitos fundamentais. Esse processo de evolução estaria diretamente relacionado com perguntas fundamentais entabuladas por Gregório Peces-Barba (1995-I, p. 104). Primeiramente questiona o autor o por que dos direitos fundamentais? Por que devem ser respeitados os direitos fundamentais? Como segundo questionamento, para quê dos direitos fundamentais? E como terceira pergunta fundamental, que podemos incluir por (Garcia, 2005, p. 420): qual deve ser seu conteúdo (?), visto que os direitos fundamentais não são um conceito estático por tratarse de um conceito que acompanha as demandas da Sociedade.
} 


\section{A concepção tridimensional dos Direitos Fundamentais no pensamento de}

\section{Gregorio Peces-Barba}

Segundo a teoria dos Direitos Fundamentais do professor Peces-Barba, os mesmos devem ser tratados a partir de uma concepção trialista ou tridimensional que leva em consideração as suas dimensões axiológicas: validade-legitimidade; normativas: vigêncialegalidade; e fática: eficácia-efetividade. Ou as dimensões éticas, jurídicas e fáticas ou sociais que formam a concepção tridimensional de Gregorio Peces-Barba. Dita concepção tridimensional dos Direitos Fundamentais terá como uma das teses centrais a visão integral do fenômeno dos direitos e será de fundamental importância para a delimitação de seu conceito de direitos fundamentais. Trarão os elementos constitutivos para o enquadramento de um direito no rol dos direitos fundamentais.

Os direitos fundamentais visando sua efetiva realização teriam seu conceito calcado em três características principais, uma relacionada com sua validade (fundamentolegitimidade), com sua vigência (positividade-legalidade) e com as práticas sociais (eficácia ou efetividade). Estas seriam as três dimensões dos direitos fundamentais: uma ética, uma jurídica e outra fática ou social.

2.1. A dimensão ética: Direitos fundamentais como uma pretensão moral justificada.

Em primeiro lugar devemos ver a dimensão ética do fenômeno, uma vez que os direitos fundamentais são uma pretensão moral justificada. Os direitos fundamentais devem ser, ou devem partir de uma pretensão moral que esteja justificada na dignidade da pessoa humana e na igualdade - seus dois pilares principais -, na liberdade, solidariedade e na segurança jurídica seus outros três pilares de sustentação -. Dito em outras palavras: os direitos fundamentais devem estar fundamentados em alguns valores básicos que foram se formando a partir da modernidade. Nos dizeres de Peces-Barba (1995-I, p. 109):

\footnotetext{
Uma pretensão moral justificada, tendente a facilitar a autonomia e a independência pessoal, enraizada nas idéias de liberdade e igualdade, com matizes que aportam conceitos como solidariedade e segurança jurídica e construída pela reflexão racional na história do mundo moderno, com as contribuições sucessivas e integradas da filosofia moral e política liberal, democrática e socialista.
}

Essa explicação da pretensão moral justificada é exatamente a fundamentação teórica do por que dos direitos fundamentais. Algo que seja contrario a dignidade da pessoa humana, ou a igualdade e a liberdade entre todos não poderá ser justificado como possível futuro direito 
fundamental. Um direito fundamental somente como pretensão moral justificada, sem ser norma positivada seria ainda um direito natural ${ }^{11}$. Essa pretensão moral justificada deve ser, portanto, positivada para ser um direito fundamental; uma vez que os direitos fundamentais devem de ter a possibilidade ou estar previstos em um texto legal. Assim estamos considerando duas das dimensões de seu conceito integral: o conceito ou visão integral dos direitos fundamentais pode ser compreendido, em primeiro lugar, sob dois pontos de vista ou dimensões: uma dimensão ética, que se traduz no caminho para fazer possível a dignidade humana e a consideração de cada ser humano como pessoa moral, e por outro lado a dimensão jurídica, que reconhece e explica a incorporação dos direitos ao direito positivo (Peces-Barba, 1995-I, p. 39). No mesmo sentido, diz o professor Peces-Barba (1995-I, p. 109) que:

Para falar de pretensão moral justificada é necessário que desde o ponto de vista de seus conteúdos seja generalizável, suscetível de ser elevada a Lei geral, é dizer, que tenha um conteúdo igualitário, atribuível a todos os destinatários possíveis, sejam os genéricos homem ou cidadão ou os situados trabalhador, mulher, administrado, usuário ou consumidor, criança, etc.

${ }^{11}$ Indiscutível a importância do Direito Natural, sobretudo o racionalista nos históricos processos de formação do ideal e de positivação dos direitos fundamentais. 
Não resta dúvida que os direitos fundamentais têm essa exigência de serem positivados, pois se ficassem somente no plano teórico de pretensão moral justificada não seriam direitos e sim somente uma idéia ou um direito natural (direitos morais prévios à positivação). Sem dúvida que o consenso acerca do direito natural racionalista - construído pelos livres pensadores do transito à modernidade - é a base do consenso acerca dos direitos fundamentais atuais. Do contrário, sem o consenso em torno aos direitos, cairíamos na critica de Jeremy Bentham no sentido de que é impossível raciocinar com fanáticos armados de um direito natural e que a variedade de direitos naturais de diversas estirpes levaria a uma horrível guerra ${ }^{12}$. Os direitos fundamentais são ideológicos e sua edificação intelectual se dá a partir de pretensões morais justificadas construídas com as contribuições sucessivas e integradas da filosofia moral e política liberal, democrática e socialista (Peces-Barba, 1995-I, p. 138144; e p. 199-204).

\subsection{A dimensão jurídica: Direitos fundamentais como possibilidade de ser uma norma} jurídica exigível.

Em segundo lugar e de acordo com sua dimensão jurídica, os direitos fundamentais devem ter a possibilidade de ser uma norma positiva, é dizer devem ter a possibilidade de

\footnotetext{
12 “(...) Es imposible razonar con fanáticos armados de un Derecho Natural que cada uno entiende a su modo, y del cual nada puede ceder ni quitar: que es inflexible, al mismo tiempo que ininteligible, que está consagrado a su vista como un dogma, y del cual nadie puede apartarse sin delito. En vez de examinar las leyes por sus efectos, en vez de juzgarlas como buenas o malas, estos fanáticos solamente las juzgan por su conformidad o contrariedad con este supuesto Derecho natural, que es decir, que sustituyen al razonamiento de la experiencia todas las quimeras de su imaginación... ¿No es esto poder las armas en manos de todos los fanáticos contra todos los gobiernos? ¿En la inmensa variedad de ideas sobre la ley natural y la ley divina, no hallará cada uno alguna razón para resistir a todas las leyes humanas? ¿Hay un solo Estado que pudiera mantenerse un día, si cada uno se creyera obligado en conciencia a resistir a las leyes que no fueran conformes a sus ideas particulares sobre la ley natural o revelada? ¿Qué guerra sangrienta y horrible entre todos los intérpretes del Código de la Naturaleza, y todas las sectas religiosas! (...).”. BENTHAM, 1981.p. 94-95.
} 
técnica jurídica de ser positivado, de ser incluído como norma jurídica. Da mesma forma não devem ser somente uma norma positiva e ponto final como se de uma declaração ou carta de intenções se tratara, uma vez que devem ser uma norma positiva que deve vir acompanhada de sua respectiva garantia. Dito de outra forma: não basta que um direito seja reconhecido e declarado, é necessário garanti-lo, porque virão momentos que será colocado em discussão, desobedecido e até sistematicamente violado. Isto é, além de positivado os direitos devem ter a possibilidade de ser exigido perante as autoridades competentes. Diz o professor Peces-Barba (1995-I, p. 112) que deve ser:

Um subsistema dentro do sistema jurídico, o Direito dos direitos fundamentais, o que supõe que a pretensão moral justificada seja tecnicamente incorporável a uma norma, que possa obrigar a uns destinatários correlativos das obrigações jurídicas que se desprendem para que o direito seja efetivo, que seja suscetível de garantia ou proteção judicial, e, por suposto que se possa atribuir como direito subjetivo, liberdade, potestade ou imunidade a uns titulares concretos.

Então os direitos fundamentais, para se tornarem efetivos devem ser uma norma positiva acompanhada dos respectivos meios, instrumentos ou procedimentos, mecanismos de técnica jurídica que a doutrina chama de garantias. Ditas garantias não são um fim em si mesmas, mas instrumentos para a tutela de um direito fundamental. Dito de forma mais completa: deve tratar-se de uma pretensão moral justificada incluída em uma norma legal acompanhada de uma garantia. Partindo dessa proposta de definição podemos averiguar que o que hoje consideramos direitos fundamentais, e que efetivamente se encontram em nosso texto constitucional como tal: uma vez que, por exemplo, todos os direitos fundamentais encontrados na Constituição da República Federativa do Brasil de 1988 são todas pretensões morais justificadas positivadas seguidas por suas respectivas garantias. Estudando as origens de todos os direitos fundamentais incluídos em nosso texto constitucional estaríamos fundamentando e justificando moralmente aquelas pretensões que se transformaram em direito positivo. A justificativa moral dos direitos fundamentais é o estudo da principal pergunta da chamada, pelos professores Gregorio Peces-Barba (1995-I, p. 104) e Nicolás Lopéz Calera (1997, p. 205-272), filosofia dos direitos fundamentais: o por quê dos direitos? Interessante também chamar a atenção no sentido de que algumas questões que podemos considerar como pretensão moral justificada e que, mesmo assim, o legislador preferiu não positivar como direitos fundamentais por serem subjetivas demais, uma vez que sua positivação pareceria pura demagogia ${ }^{13}$.

${ }^{13} \mathrm{O}$ amor, por exemplo, sem nenhuma dúvida trata-se de uma pretensão moral justificadíssima, todo ser humano tem direito a amar e ser amado. É uma questão indiscutível, mas como poderíamos incluir uma norma de direito fundamental que fale do amor. O amor é subjetivo demais, o que é amor para uma pessoa pode não ser para outra. Uma vez declarado o amor um direito fundamental, como seria sua garantia? 


\subsection{A dimensão fática ou social: Direitos fundamentais como realidade social $\mathrm{e}$} condições essenciais para sua efetividade.

Em terceiro lugar e de acordo com sua dimensão fática ou social, os direitos fundamentais são uma realidade social, é dizer, atuante na vida social, e por tanto condicionados na sua exigência por fatores extrajurídicos de caráter social, econômico ou cultural que favorecem, dificultam ou impedem sua efetividade (Peces-Barba, 1995-I, p. 112). Certamente impossível separar os direitos fundamentais da realidade social. A realidade social, o meio no qual será aplicado será fundamental para sua eficácia ou não. Dependerá de uma serie de fatores como a conscientização da sociedade em relação aos seus direitos fundamentais e às suas prerrogativas como cidadão; da vontade política da sociedade e de suas autoridades; das políticas públicas a serem incrementadas e que sejam verdadeiramente favoráveis aos menos favorecidos e aos direitos fundamentais de todos, a existência de uma real educação para a cidadania que preze por uma visão integral do conceito dos direitos fundamentais, é dizer que leve em consideração os direitos fundamentais como direitos inclusivos, de todos. Muitos outros fatores relacionados com a realidade social poderiam ser aludidos.

Um dos graves problemas da época atual para a efetividade dos direitos fundamentais é exatamente a não consideração de sua realidade social. A denominada, por Peces-Barba (1995-I, p. 61-62), principal negação parcial da atualidade, a teoria neoliberal, não considera os direitos sociais como direitos fundamentais. A falácia neoliberal leva a não efetividade dos direitos fundamentais uma vez prescinde não somente de sua segunda geração - os direitos sociais -, mas também de uma das dimensões do conceito ou visão integral dos direitos fundamentais. A visão integral do conceito dos direitos fundamentais exige uma reflexão sobre a dimensão ética e jurídica e também com relação a sua dimensão social. A dimensão social da visão integral dos direitos é a que tem relação com sua incidência social, isto é incidência real de fatores econômicos, sociais e culturais (Peces-Barba, 1995-I, p. 40). Todos fatores importantíssimos para uma verdadeira efetividade dos direitos fundamentais. Sobre os Direitos como direitos de todos e de acordo com seu conceito integral, diz o professor Peces-Barba (1995-I, p. 112):

Assim o analfabetismo, dimensão cultural, condiciona a liberdade de imprensa; e os
progressos da técnica em um determinado momento da cultura científica, por exemplo,
com os progressos das comunicações, condicionam a idéia de inviolabilidade de
correspondência; ou a escassez de bens pode condicionar ou impedir, tanto para a
existência de uma pretensão moral à propriedade pelo seu impossível conteúdo
igualitário, quanto de uma norma jurídica pela impossível garantia judicial.

A efetividade é um conceito ambivalente na teoria do Direito para sinalizar a influência do Direito sobre a realidade social ou, ao contrario, da realidade social sobre o Direito (PecesBarba, 1995-I, p. 112). Em latitudes como a nossa, o segundo suposto é o mais importante. No 
primeiro suposto se trata do impacto do Direito sobre a sociedade, de seus níveis de seguimento ou de obediência, e no segundo do condicionamento da justiça ou moralidade das normas ou de sua validade ou legalidade, por fatores sociais. Este é o suposto ao que fazemos alusão como terceiro e mais importante componente para a compreensão da efetividade ou não dos direitos fundamentais, uma vez que não dependem somente de serem valor moral e norma.

A história dos direitos fundamentais, que é também a história da luta pela dignidade humana, faz parte do patrimônio da humanidade. E esse patrimônio da humanidade deve ser ensinado através de uma educação igualitária que dê oportunidade para todos. Não resta dúvida que os direitos fundamentais são conquistas históricas da humanidade, e estas conquistas históricas devem ser valorizadas e divulgadas a partir de uma educação para os direitos humanos e a cidadania. O filósofo Voltaire (2007, p. 14-15) já argumentava no sentido de que um povo tem que aprender com sua história e com a história da humanidade. Não cabe dúvida que falta de conhecimento histórico, a ignorância leva ao fanatismo e a barbárie. Devemos sempre recordar para as futuras gerações as lições da história, assim carece ser lembrada sempre, por exemplo, a idéia de banalização do mal de Hannah Arendt (1999, p. 336), e seu sentimento humano de impotência e indignação diante da burocratização do mal em sua histórica análise sobre o julgamento de Eichmann. Somente através de uma cultura que parte de uma educação calcada nos valores da cidadania e dos direitos fundamentais é que poderemos reivindicar a utopia dos direitos humanos para a construção de um mundo melhor.

É certamente o inicio do século XXI o momento (infelizmente tardio) em que nosso país e toda a humanidade devem entender e estudar o fenômeno dos direitos fundamentais e fazer deles em cada canto do mundo parte da cultura e da educação local e assim poder entender e enfrentar o global. Não olvidando a lição do professor Nicolás López Calera (1998, p. 134) no sentido de que "não devemos esquecer que todos os direitos humanos, em maior ou menor medida, são independentes, pelo que sua efetiva realização exigirá uma luta global que não descuide 
nenhum aspecto fundamental da complexa realidade do ser humano", e para tal faz-se necessário promover uma civilização e uma cultura facilitadoras da educação na solidariedade, na tolerância e em diversos outros valores fundamentais para chegar a uma educação dos direitos humanos ${ }^{14}$.

De nada adianta termos uma pretensão moral justificada positivada e seguida de sua respectiva garantia, quando a realidade social é contrária aos direitos fundamentais, da mesma forma que contrária a igualdade e da implementação de uma sociedade mais justa e solidária ${ }^{15}$.

\section{Critérios para determinar se um Direito pode ser incluído no rol dos Direitos} Fundamentais a partir da concepção tridimensional de Gregorio Peces-Barba

Partindo do estudo da concepção tridimensional dos Direitos Fundamentais de Gregorio Peces-Barba pode-se estabelecer alguns critérios para caracterizar os Direitos Humanos. Essa é a visão integral dos Direitos de Peces-Barba. Se um direito não contém em si - não satisfaz - todas as dimensões, não deve ser considerado um autêntico Direito Fundamental ou Direito Humano. São estas característica que devem compor o conceito de Direitos Fundamentais proposto pelo professor espanhol. Algumas características que devem ter os Direitos Humanos:

\footnotetext{
14 “Es necesario promover una civilización y una cultura que faciliten la educación en la solidariedad. Es necesario fomentar la virtud de la solidariedad en un mundo en el que unos pocos tiene derechos y muchos tienen pocos derechos o casi ninguno”. LÓPEZ CALERA, 1997, p. 134 (Grifos no original).
} 
3.1. Um autêntico Direito Fundamental deve incluir as três dimensões: uma visão integral do conceito

Uma vez que um pretenso direito candidato a ser fundamental, seja um conteúdo normativo ou qualquer pretensão moral que é reivindicada como direito, que não tenha possibilidades de cumprir com as três dimensões antes descritas, não poderá ser considerado como um direito fundamental. É dizer, não poderá ser incluído no rol dos direitos humanos, constitucionalizados ou não. A afirmativa é feita tendo em consideração a concepção tridimensional de Gregorio Peces-Barba. Dependendo da dimensão que apresente problemas ou que seja inexistente pode-se estar diante de:

a) uma norma injusta, mas válida judicialmente e eficaz. Como exemplo: normas injustas que perpetuam diferenças entre poderosos e oprimidos em diversas sociedade. Essa é a questão dos direitos humanos violados em nome dos próprios direitos humanos. O Direito pode ser utilizado para promover tanto o progresso do ser humano como o estancamento da Sociedade. Em particular a relação do Direito com a Sociedade revela que o direito se mostra - em muitas vezes e em algumas latitudes - como reacionário e relutante às modificações, enquanto que a dinâmica interna da Sociedade procura transformações mais rápidas. O caráter transformador e revolucionário dos Direitos Fundamentais é certamente a luz do final do túnel dos povos, a saída de seus problemas sociais mais graves, sobretudo dos mais oprimidos e dos mais débeis. Para Peces-Barba um bom exemplo seria o Direito de propriedade, que motivado pela problemática da escassez, não pode ser fundamentado como um direito humano fundamental, como veremos a seguir. As consequências de um direito não-fundamental tipificado como fundamental são gravíssimas e servem para perpetuar injustiças. Como exemplo a suposta colisão de direitos fundamentais no conhecido Caso Pinheirinho em

\footnotetext{
${ }^{15}$ No mesmo sentido deve ser considerada a tese da constitucionalização simbólica do professor Marcelo Neves (2007, 288 p.); assim como a noção de democracia substancial e outras questões discutidas na obra de Luigi Ferrajoli (2001. Especificamente: parte V, p. 849-957); e mais recentemente a também relevantíssima obra Los derechos sociales y sus garantías de Gerardo Pisarello (2007, 144 p.).
} 
São Paulo (Moradia X Propriedade), de acordo com a decisão do judiciário paulista no caso em concreto prevaleceu á propriedade de um senhor (especulador imobiliário e conhecido ficha suja) contra o Direito Fundamental à moradia de mais de duas mil famílias. Injustiça absurda em nome de um pretenso direito fundamental.

b) uma norma justa e válida judicialmente, mas ineficaz. Como por exemplo as chamadas em nosso meio como normas para inglês ver, normas que não são eficazes por razões políticas e fáticas em situações e práticas sociais em que os donos do poder e a mentalidade vigente não deixam que sejam eficazes. Como no caso do Brasil a ineficácia de uma série de Direitos Fundamentais se deve, como ensina o professor PecesBarba, a que os direitos fundamentais são acima de tudo uma mudança de mentalidade. Outro exemplo clássico, seria aquele de uma constituição avançada em uma sociedade atrasada, de mentalidade retrógada contra os direitos humanos, como o caso do Estatuto da Criança e do Adolescente, ainda não compreendido numa sociedade ainda com abismais diferenças sociais e de origem escravocrata. Também importante aqui dar ênfase na participação da mídia brasileira na mentalidade conservadora dos brasileiros com relação aos direitos humanos, no sentido que o refrão "direitos humanos somente servem para proteger bandidos" ainda está na ordem do dia ${ }^{16}$.

\footnotetext{
${ }^{16}$ Recorremos ao professor italiano Arnaldo Miglino(2010, p. 130) para argumentar quando fala de que uma mídia plural seria necessária para que o público possa melhor reconstituir os fatos, comparar ideias diferentes e assim poder expressar uma visão crítica sobre eles, somente "(...) assim vigiar quem controla o poder". Segue acertadamente o professor italiano no sentido de que "A falta de pluralismo da informação permite escondê-la [a verdade] e promove a verdade da mentira, razão pela qual a informação controlada por um número reduzido é um fenômeno antidemocrático". Na mesma linha que Ferrajoli faz quando escreve desde o seu Derecho y Poder dos anos 1980, e recentemente em Poderes Salvajes, denunciando os poderes selvagens que seriam exatamente o poder econômico na manipulação dos fatos, Arnaldo Miglino segue: "(...) Se que detém os meios de comunicação deles se utiliza a fim de tornar detentor do poder político e econômico ou para mantê-lo, ocorre um fenômeno totalmente alheio ao sistema democrático, ou seja, quem deve ser controlado detém o controle da cosnciência crítica de seus controladores". Também fazemos referência que desde o título poderes selvagem (poteri selvaggi) Ferrajoli $(2011,109$ p.) alude a questão do uso da liberdade sem lei da qual fala Kant como o poder do mais forte, atribuindo assim um componente de animalidade aos poderes sobretudo econômico da atualidade do panorama que pressiona à Sociedade na crise do constitucionalismo democrático.
} 


\section{c) uma pretensão moral justificada que deveria ser uma norma de direito}

fundamental, mas que não é positivada por motivos políticos e sociais. Afirma Luigi Ferrajoli $(1999,180$ p.) que os direitos fundamentais são reivindicações dos mais débeis. As lutas sociais por reivindicações de direitos levam algumas vezes séculos ou décadas, já que muitas vezes devem esperar uma lenta mudança de mentalidade da sociedade. Somente a educação e a cultura a favor do ser humano e da cidadania levam a conscientização das diferentes situações de opressão dos mais débeis. A história nos indica que os direitos fundamentais nascem de reivindicações dos mais fracos. Isso se dá sempre a partir de grupos dos mais fracos e débeis perante o grupo dos mais fortes e poderosos. Então o burguês reivindicará direitos ante as classes privilegiadas, nobreza e alto clero, e o monarca. Posteriormente os sans-culotte, proletariado ou trabalhador, desesperadamente reivindicará direitos ante uma forte burguesia dona do poder. E assim sucessivamente, os grupos mais fracos da sociedade, a mulher, o idoso, a criança, o consumidor, o cidadão vítima das graves contaminações do meio ambiente, etc., estes e outros irão reivindicar direitos ante os poderosos, seja homem, adulto, rico, produtor de bens de consumo, e o poluidor por interesses econômicos de todo o planeta;

d) uma pretensão moral justificada que muitos reivindicam sua positivação, mas que não tem condições de ser uma norma de direito fundamental, uma vez que seria impossível mesurar sua eficácia por culpa do seu alto teor de subjetividade, assim como impossível sua garantia. O exemplo é o caso do afeto, do amor e da felicidade, todas pretensões morais justificadas mas que não poderiam ser uma norma positiva de direito por seu alto teor de subjetividade e impossibilidade de sua garantia. Sua positivação sem a possibilidade de sua garantia, teria uma aparência de pura demagogia, que é uma deturpação da democracia na clássica classificação de Aristóteles. $O$ professor Nicolás López Calera (1997, p. 210) chama a atenção para o perigo da inflação e falta de critérios para a adoção de novas situações como direitos fundamentais. A subjetividade desses pretensos direitos fundamentais prejudicam as suas respectivas garantias. Como iríamos garantir o afeto, o amor e a felicidade?

Enfim, muitas são as possibilidades de combinações que permitem as dimensões de justiça, validade e eficácia, assim como os respectivos exemplos, para averiguar 
quando não estamos diante do que a cultura ocidental moderna e contemporânea tem por costume chamar de Direitos Fundamentais ou Direitos Humanos. Um autêntico Direito Fundamental deve incluir as três dimensões: a de justiça/ética; a de validez/jurídica e a fática/eficácia. Essa é a visão integral do conceito de Gregorio Peces-Barba.

3.2. Um autêntico Direito Fundamental deve incorporar todos os demais critérios dados pela visão integral do conceito: alguns testes para averiguar as possibilidades de incorporação de um direito no rol dos Direitos Fundamentais

$\mathrm{Na}$ defesa da necessidade do aporte positivista dos direitos fundamentais, argumenta Peces-Barba (1995-I, p. 104), que não haveria sentido falar de fundamentação de um direito que não seja depois suscetível de integrar-se ao Direito positivo. Em nossa interpretação: Teste inicial de averiguação. Questão da positividade dos direitos: tem a possibilidade de ser uma norma de Direito?

Também, na defesa da necessidade do aporte ético, leciona Peces-Barba (1995-I, p. 104) que não tem sentido falar de um conceito de um direito, ao que não se possa encontrar uma raiz ética vinculadas às dimensões centrais da dignidade da pessoa humana. Em nossa interpretação chama-se a atenção para esse elemento fundamental dos direitos humanos: vinculação com a dignidade da pessoa humana. Teste número 1 de averiguação. Questão da Dignidade da Pessoa Humana: o não atendimento de tal direito viola a dignidade da pessoa humana? Se chegamos a conclusão que uma pretensão é justificada moralmente e com uma aparência de direito fundamental em potência, dessas que alguns autores chamam de direito natural ou mesmo "direitos morais" não se pode positivar, em nenhum caso, por razões de validez, ou de eficácia, por não ser suscetível de converter-se em norma ou por não poder aplicar-se. Em nossa interpretação: questão da sua relação com as garantias. Teste número 3 de averiguação. Questão das Garantias: pode-se garantir através do Direito tal questão? Exatamente será Luigi Ferrajoli o autor fundamental da distinção entre Direitos e Garantias, posição bem conhecida entre os estudiosos da Teoria do Direito contemporânea ${ }^{17}$.

A seguinte questão lançada por Peces-Barba (1995-I, p. 104), e que em seu entorno gerou mais polêmica, é a questão da igualdade e da escassez. Um pretenso direito fundamental por sua impossibilidade de conteúdo igualitário, por uma questão de escassez de meio de bens não poderá ser considerado um direito humano fundamental, não poderá 
ser incluído no rol dos Direitos Fundamentais. Em nossa interpretação é a questão da igualdade e da garantia isonômica a todos os membros da sociedade humana. Teste número 2 de averiguação: Questão da igualdade: pode-se garantir a todos os membros da sociedade e da família humana? Em situações de escassez, uma vez que não pode ser garantido a todos, não poderíamos considerar essa fundamentação relevante como a de um direito humano.

Para Peces-Barba (1993, p. 422), são principalmente dois os exemplos das consequências que a inclusão de sua reflexão sobre a escassez, em sentido forte, pode causar em uma teoria dos direitos fundamentais: o direito de propriedade e o direitos ao trabalho. Esse último entendido como: o direito a "obter um posto de trabalho, geralmente construído como obrigação dos poderes públicos" (com o qual não se exclui do conceito de Direitos Fundamentais, para Peces-Barba, a liberdade de trabalho, a estabilidade trabalhista e todos os outros aspectos relacionados com esse direito, como por exemplo consagrados na Constituição da República Federativa do Brasil, continuam e que evidentemente são autênticos Direitos Fundamentais). Para o professor madrilenho ambos direitos são afetados pela escassez em sentido forte, já que para ele é impossível que todas as pessoas da família humana que são seus destinatários, se lhes possa brindar um posto de trabalho ou a propriedade sobre determinados bens. Os

\footnotetext{
17 Para Ferrajoli os Direitos Fundamentais são direitos subjetivos dos quais derivam qualquer expectativa positiva (de prestação) ou negativa (de não sofrer lesões) pertencentes a um sujeito por uma norma jurídica. Por garantias deve-se entender toda obrigação correspondente a um direito subjetivo (consistentes em obrigações ou proibições, que correspondem aos direitos subjetivos garantidos), que podem ser positivas ou negativas e garantias secundárias ou jurisdicionais (para fazer referência às obrigações que têm os órgãos jurisdicionais de aplicar sanção ou declarar a nulidade quando se constatem, no primeiro caso atos ilícitos e no segundo atos não válidos que violem direitos subjetivos e com isso suas correspondentes garantias primárias). Ambos tipos de garantias têm funções distintas, as primárias estão orientadas à satisfação material dos direitos, enquanto que as secundárias operam um segundo nível como remédio disposto para a reparação da inobservância das primeras representadas pelos atos ilícitos ou pelos atos inválidos. FERRAJOLI, Luigi. Garantías. Jueces para la democracia. n.38. 2000. p. 40-43. Da mesma forma: FERRAJOLI, Luigi. Sobre los derechos fundamentales. In: CARBONELL, Miguel. Teoría del neoconstitucionalismo: ensayos escogidos. Madrid: Trotta, 2007. p. 71-89.
} 
condicionamentos sociais como a pobreza e a limitação dos recursos o impedem. Por isso acredita Peces-Barba (1995-I, p. 421-423) que a ambos "(...) afeta a questão da escassez e por conseguinte ambos participam de um impossível conteúdo igualitário que produz, a sua vez, a impossibilidade de ser elevados a uma generalização". Conclui, "Não podem ser direitos fundamentais".

3.3. Um autêntico Direito Fundamental deve ser igual para todos: a questão da escassez

Somente através da cultura pode-se chegar à inclusão dos direitos fundamentais na mentalidade comportamental de um país ou de um povo. Os direitos fundamentais têm essa fundamental característica de serem inclusivos, isto é, como diz o professor Sergio Cademartori (2007, p. 29), “(...) não pode cada um gozar dos mesmos se simultaneamente os outros também não usufruem deles". A mudança de mentalidade da sociedade é a única possibilidade de arraigar a consciência dos direitos fundamentais como reais valores a serem considerados. Desta maneira, então algumas características dos direitos fundamentais devem ser amplamente debatidas visando construir uma realidade social mais favorável aos mesmos.

A questão da escassez, tratada por Gregorio Peces-Barba (especificamente, 1995-III, p. 193-213) em muitos pontos de sua obra é de suma importância para entender a impossibilidade de enquadramento da propriedade como um direito humano fundamental. Uma vez que a propriedade não é generalizável, igualitária, não se pode garantir a todos, exatamente por ser um bem escasso. Assim sendo pelo aludido problema da escassez, segundo o professor espanhol, não podemos incluir o direito à propriedade no rol dos Direitos Fundamentais.

A consideração do direito de propriedade como um direito do homem é um dos pilares das revoluções liberais burguesas dos séculos XVII e XVIII. Como os direitos fundamentais não são um conceito estático, e sim um conceito dinâmico - uma vez que o processo de formação do ideal dos direitos fundamentais é constante-, novas demandas e reivindicações de direitos fundamentais estão presentes em cada momento histórico da sociedade humana. Como já foi dito, a história nos indica que os direitos fundamentais nascem de reivindicações dos mais débeis. Isso se dá sempre a partir de grupos dos mais fracos e débeis perante o grupo dos mais fortes e poderosos. Um direito 
que nunca pensava-se que poderia existir surge como uma nova demanda, um novo direito; e em contrapartida: um direito consagrado em um determinado momento histórico pode deixar de ser um direito fundamental. Este último caso seria o da propriedade. Consagrado como um dos pilares do processo de positivação dos direitos do homem e do cidadão a partir das revoluções liberais, hoje em dia pode-se afirmar que há deixado de ser um direito fundamental.

Para poder falar da negação do direito de propriedade como um dos direitos fundamentais em Gregorio Peces-Barba, faz-se necessário averiguar sua concepção tridimensional dos Direitos Fundamentais. Como foi explicitado, dita concepção tridimensional dos Direitos Fundamentais do professor Gregorio Peces foi a assim batizada por um dos seus principais discípulos, o professor Rafael de Asís Roig. Na construção e delimitação do conceito de Direitos Fundamentais na obra do professor Peces-Barba, em uma primeira fase de seu pensamento era notadamente dualista, entre as dimensões ética e jurídica. Rafal de Asís disserta que nos anos de 1990 a teoria do direito do professor madrilenho passa a ser trialista, ou seja uma concepção tridimensional (por exemplo: Peces-Barba, 1995-I, 423 p.)

Em muitas oportunidades mesmos as teorias mais avançadas -no sentido de transformadoras, revolucionárias e progressistas -no sentido que visam um real desenvolvimento humano-, com uma matriz bem intencionada, acabam por levar ao engodo de práticas e interpretações mal-intencionadas e retrógadas. Dito de outra maneira, os próprios Direitos Fundamentais podem ser utilizados contra os seus ideais libertadores e transformadores da Sociedade e de suas mazelas endêmicas. Nesse sentido chamase a atenção sobre de como teorias sofisticadas de aplicação de princípios constitucionais oriundas de autores de outras latitudes, a partir de outras realidades sociais, são aplicadas e mal-intencionadamente deturpadas em nosso país.

Certamente é mais ou menos nesse ponto que entra no debate a questão da terra, da propriedade - do direito à propriedade- em nosso país. O direito à propriedade deveria ser limitado e submetido à legislação infraconstitucional como propõe Gregorio Peces-Barba e ter tratamento de direito patrimonial como propõe Luigi Ferrajoli (2009, p. 30). Limitado também por sua elementar condição de ser submetido à utilidade pública, pilar da modernidade, e/ou da contemporânea função social. Dar a terra a quem nela vive e trabalha é um dos pilares das revoluções liberais burguesas do século XVIII. 


\section{Considerações Finais}

A partir da concepção tridimensional dos Direitos Fundamentais de Gregorio Peces-Barba podemos estabelecer as seguintes características conceituais do mesmos:

Um direitos fundamental deve estar sustentado nos pilares de pretensão moral justificada (dignidade da pessoa humana, igualdade, liberdade. solidariedade e segurança jurídica); e para ser uma pretensão moral justificada deve passar pelos seguintes testes e indagações:

1) da dignidade da pessoa humana (sua violação ou não atendimento violam a dignidade da pessoa humana?);

2) da igualdade (podem ser garantidos a todos os membros da sociedade humana? ou seja, não encontramos o problema da escassez?);

3) das garantias (dito direito podem ser tecnicamente garantidos?).

Essa mesma pretensão moral depois de justificada deve ser positivada, ser uma norma de Direito Fundamental ou um Direito Humano previsto em um documento internacional ratificado internamente. Deve ser direito positivo, do contrário será uma reivindicação, um direito natural ou um direito moral, mas não um direito fundamental.

E por fim, deve estar de acordo com a realidade social, deve ter aplicabilidade efetiva. Eficácia imediata, ser exigido diretamente e acatado pelas autoridades e por toda a população, uma questão de mentalidade.

\section{Referências das Fontes Citadas}

ARENDT, Hannah. Eichmann em Jerusalém: um relato sobre a banalidade do mal. Tradução de José Rubens Siqueira. São Paulo: Companhia das Letras, 1999. 
ASÍS ROIG, Rafael de. La concepción dualista de los Derechos Fundamentales en la teoría de Gregorio Peces-Barba. In: VV.AA. Entre la Ética, la Política y el Derecho. Estudios en homenaje al profesor Gregorio Peces-Barba. Vol. I. Madrid: Dykinson, 2008. p. 391-406.

ASÍS ROIG, Rafael de. Sobre el concepto y el fundamento de los Derechos: una aproximación dualista. Madrid: Dykinson/Universidad Carlos III de Madrid, 2001.BENTHAM, Jeremy. Tratados de legislación civil y penal. Tradução de Ramón Salas. Madrid: Editora Nacional, 1981.

BOBBIO, Norberto. A Era dos Direitos. Tradução de Carlos Nelson Coutinho. 7 ed. Rio de Janeiro: Elsevier, 2004.

CADEMARTORI, Sergio. Estado de direito e legitimidade: uma abordagem garantista. 2.ed. Campinas: Millennium, 2007.

DORADO, Javier. El positivismo "corrigido": análisis de algunos aspectos de la filosofía jurídica de Gregorio Peces-Barba. In: VV.AA. Entre la Ética, la Política y el Derecho: Estudios en homenaje al profesor Gregorio Peces-Barba. Vol. I. Madrid: Dykinson, 2008. p. 429-453.

FERNÁNDEZ GARCIA, Eusebio. Gregorio Peces-Barba: apuntes biográficos. In: VV.AA. Entre la Ética, la Política y el Derecho: Estudios en homenaje al profesor Gregorio Peces- Barba. Vol. I. Madrid: Dykinson, 2008. p. 453-463.

FERRAJOLI, Luigi. Los fundamentos de los derechos fundamentales. 4. ed. Madrid: Trotta, 2009.

FERRAJOLI, Luigi. La esfera de lo indecidible y la división de los poderes. In:

Democracia y garantismo. Tradução de Perfecto A. Ibáñes, et al. Madrid: Trotta, $\overline{2008 \text {. p. }}$ 102-109.

FERRAJOLI, Luigi. Derechos y garantías: la ley del más débil. Tradução de Perfecto A. Ibáñes e Andréa Greppi. Madrid: Trotta, 1999.

FERRAJOLI, Luigi. Garantías. Jueces para la democracia. n.38. 2000.

FERRAJOLI, Luigi. Poderes Salvajes: la crisis de la democracia constitucional. Tradução de Perfecto A. Ibáñez . Madrid. Trotta, 2011.

FERRAJOLI, Luigi. Sobre los derechos fundamentales. In: CARBONELL, Miguel. Teoría del neoconstitucionalismo: ensayos escogidos. Madrid: Trotta, 2007. p. 71-89.

FERRAJOLI, Luigi. Derecho y razón: Teoría del garantismo penal. 4.ed. Tradução de Perfecto A. Ibáñez. Madrid: Trotta, 2001. Especificamente: parte V, p. 849-957.

GARCIA, Marcos Leite. A contribuição de Christian Thomasius ao processo de formação do ideal dos direitos fundamentais. Revista Novos Estudos Jurídicos. Itajaí, v. 10, n. 2, p. 417 450, jul./dez. 2005.

GARCIA, Marcos Leite. Efetividade dos Direitos Fundamentais: notas a partir da visão integral do conceito segundo Gregorio Peces-Barba. In: VALLE, Juliano Keller do; MARCELINO JR., Julio Cesar. Reflexões da Pós-Modernidade: Estado, Direito e Constituição. Florianópolis: Conceito Editorial, 2008. p. 189-209. 
GARCIA, Marcos Leite. O processo de formação do ideal dos Direitos Fundamentais: alguns aspectos destacados da gênese do conceito. In: Anais do XIV Congresso Nacional do CONPEDI. Florianópolis: Boiteux, 2006. <http://www.conpedi.org/manaus/anais_conpedi.html> Acesso: 15 de março de 2015.

GARCIA, Marcos Leite. Uma proposta de visão integral do conceito de direitos fundamentais. In: Âmbito Jurídico, Rio Grande, 46, 10.2007. Disponível em:<www.ambitojuridico.com.br/site/index.php?n_link=revista_artigos_leitura\&artigo_id=2343 $>$ Acesso: 15 de março de 2015.

GUASTINI, Riccardo. La "constitucionalización" del ordenamiento jurídico: el caso italiano. In: CARBONELL, Miguel. Neoconstitucionalismo (s). Madrid: Trotta, 2003. p. 49-73.

HIERRO, Liborio. En busca del arca perdida: diez comentarios a las tesis de Gregorio PecesBarba sobre el fundamento de un sistema jurídico. In: VV.AA. Entre la Ética, la Política y el Derecho: Estudios en homenaje al profesor Gregorio Peces-Barba. Vol. I. Madrid: Dykinson, 2008. p. 639-661.

LOPEZ CALERA, Nicolás María. Filosofía de los derechos humanos: dialéctica y paz social. In: OLIVEIRA JR., J. Alcebíades. O poder das metáforas: homenagem aos 35 anos de docência de Luis Alberto Warat. Porto Alegre: Livraria do Advogado, 1998, p. 128-143. .

LOPEZ CALERA, Nicolás María. Filosofía de los derecho (I). Granada: Editorial Comares, 1997.

MIGLINO, Arnaldo. A Cor da Democracia. Florianópolis: Conceito, 2010.

NEVES, Marcelo. A constitucionalização simbólica. São Paulo: Martins Fontes, 2007.

PECES-BARBA, Gregorio. Curso de Derechos Fundamentales: teoría general. Madrid: Universidad Carlos III de Madrid, 1995-I.

PECES-BARBA, Gregorio. Derecho y Derechos Fundamentales. Madrid: Centro de Estudios Constitucionales, 1993.

PECES-BARBA, Gregorio. Derecho sociales y positivismo jurídico: escritos de Filosofía Jurídica y Política. Madrid: Dykinson/Universidad Carlos III de Madrid, 1999.

PECES-BARBA, Gregorio. Escasez y Derechos Humanos. In: SAUCA, José María (org.). Problemas actuales de los Derechos Fundamentales. Madrid: Universidad Carlos III de Madrid, 1995-III. p. 193-213.

PECES-BARBA, Gregorio. Ética, Poder y Derecho. Madrid: Centro de Estudios Constitucionales, 1995-II.

PECES-BARBA, Gregorio. Ética pública-ética privada. Anuario de Filosofía del Derecho. Vol. XIV, p. 513-544, 1997;

PECES-BARBA, Gregorio. La España civil. Barcelona: Galaxia Gutenberg, 2005.

PECES-BARBA, Gregorio. Persona, Sociedad, Estado: pensamiento social y político de Maritain. Madrid: Cuadernos para el Diálogo, 1972.

PECES-BARBA, Gregorio. Tránsito a la Modernidad y Derechos Fundamentales. Madrid: Mezquita, 1982. 
PECES-BARBA, Gregorio. Los noventa años de Bobbio. El País, Madrid, p. 25, 7 jan. 2000.

PECES-BARBA, Gregorio. Prólogo. In: Bobbio. Autobiografía. Madrid: Taurus, 1998.

PISARELLO, Gerardo. Los derechos sociales y sus garantías. Madrid: Trotta, 2007.

VOLTAIRE. A filosofia da história. Tradução de E.Brandão. São Paulo: Martins Fontes, 2007. 